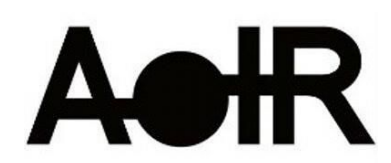

Selected Papers of \#AolR2018: The $19^{\text {th }}$ Annual Conference of the Association of Internet Researchers Montréal, Canada / 10-13 October 2018

\title{
"THIS MEME IS WHAT WE CALL PROGRESS": HISTORY-AS-MEME, MEME-AS-HISTORY ON 4CHAN
}

Sean McEwan, University of Illinois-Chicago

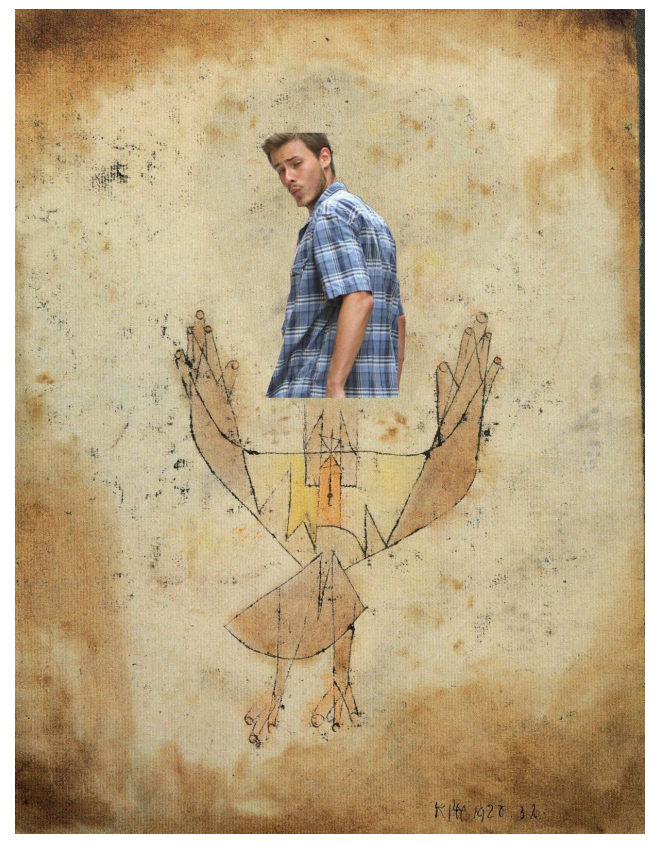

Figure 1: A variation of the "Distracted Boyfriend" meme, which combines the titular unfaithful partner with Angelus Novus 
Memes "act as the locus of memory", says Gabriella Coleman of the peculiar relationship 4chan has to its own history. ${ }^{1}$ Rather than having an on-site permanent archive as such, its collective history and memory is sublated into and through the circulation and production of memes: as Herwig describes, it is "the archive as the repertoire". ${ }^{2}$ This paper builds upon Herwig to consider how the (re)production, circulation, and referencing of memes serve as embodiments of specific historical ontologies: modes of being constructed in relationship to, and through, their own past(s). ${ }^{3}$ Not only do memes serve to "propagate and strengthen certain visions of cultural memory", but the specificities of their cultural production and dissemination on 4chan have a temporal politics, that imparts "a sense of historical origins, spiritual rootedness and re-enchantment to its hypermodernity". ${ }^{4}$ The potentially infinite malleability of memes, yet the restriction of what constitutes memetic worth to that which re-affirms a specific temporal and technological presence, forms a "reactionary (post)modernism". ${ }^{5}$ The purpose of the paper is twofold. First I wish to add to existing meme research a case for consideration of their temporal politics. Secondly, I wish to link an historical ontology on 4chan and the conditions of possibility thereof to its continued capacity as a wellspring of revolutionary conservatism. In this I follow work by el-Ojeili that focuses on post-fascism's "positive, reconstructive, and utopian elements".

To animate this discussion I use Benjamin's famous Thesis IX from "Theses on the Philosophy of History", and his reading of Paul Klee's Angelus Novus: the Angel of History looking backwards, watching the wreckage of past events accumulate before it, wanting to "awaken the dead and piece together what has been smashed". ${ }^{7}$ The Angel is blown forward by a storm, a storm called Progress. And so it is with successful meme-making on 4chan: in order for memes to "succeed", and indeed in part for them to even be recognised as memes, there requires a transformation of old content. At the same time, enough needs to be kept of the original content so that this transformation can be recognised. Previous work has described the deployment of memes as a means

\footnotetext{
${ }^{1}$ Coleman, "Net Wars over Free Speech, Freedom, and Secrecy or How to Understand the Hacker and Lulz Battle against the Church of Scientology."

${ }^{2}$ Herwig, "The Archive as the Repertoire. Mediated and Embodied Practice on Imageboard 4chan.Org."

${ }^{3}$ Foucault, "What Is Enlightenment?", 49.

${ }^{4}$ Swiatek, "Constructing Cultural Memory: A Memetic Approach", 129.; Griffin, "Fixing Solutions: Fascist Temporalities as Remedies for Liquid Modernity", 15.

${ }^{5}$ I combine here Herf's use of "reactionary modernism" to describe Nazism's tension between its anti-Enlightenment values and adoption of technology with Grossberg's description of the postmodern sensibility in We Gotta Get Out of This Place as a "logic of ironic nihilism". Herf, Reactionary Modernism: Technology, Culture and Politics in Weimar and the Third Reich; Grossberg, We Gotta Get Out of This Place, 224.

${ }^{6}$ el-Ojeili, "Reflecting on Post-Fascism: Utopia and Fear", 3.

${ }^{7}$ Benjamin, "Theses on the Philosophy of History", 257.
} 
by which digital communities police their identities and garner cultural capital. ${ }^{8}$ I would add to this that opportunities for users to gain cultural capital are predicated upon the perceived availability of positions within the field: that memes are "distinctive signs that are understood and perceived by digital inhabitants and that are misunderstood or passed over by others". ${ }^{9}$ This demarcates the meme savvy (insiders) from the Normie (outsiders). ${ }^{10}$

This takes place in a digital environment saturated in the habitus of the new, "a set of dispositions that are invited and regenerated via a state of permanent novelty". ${ }^{11}$ As Bourdieu says, 4chan users measure "all practices against the yardstick of their own taste, the acid test of modernity". ${ }^{12}$ So as the "pile of debris... grows skyward" in the forms of memes exhausted of potential capitalisation, meme-savvy users are driven forward to find new value..$^{13}$ In the process of making, (re)posting, and commenting upon memes in specific digital environments, users collectively participate in both the process of writing the histories of their communities, and embodying them. Constituted with the creation of a new meme that ironically re-appropriates or (re)contextualises certain features of an earlier, spent meme, there is a history: it tells the tale of (their) community that previously used, but discarded, this meme, but, through application of "vernacular creativity" that acknowledges, and moves past, this history, a meme is (re)made into an object (once again) worthy of esteem, consideration, and dissemination. ${ }^{14}$ The battle that happens over correct usage of memes not only defines their subculture spatially, but temporally, with memers the avant garde positioned against the Johnny-come-lately Normie.

Rather than 4chan users relying upon a stable canon of memes, 4chan "demands that users as body-subjects engage and participate". ${ }^{15}$ Memes, in other words, hold no worth merely sitting idle but must be performed anew, blown forward. Previous research has outlined some of the technical affordances of 4chan-as-website, such as its lack of persistent user identity and the "ephemeral, transitory and fleeting" content of the

\footnotetext{
${ }^{8}$ Literat and van den Berg, "Buy Memes Low, Sell Memes High: Vernacular Criticism and Collective Negotiations of Value on Reddit's MemeEconomy"; Nissenbaum and Shifman, "Internet Memes as Contested Cultural Capital: The Case of 4chan's /b/ Board"; Milner, "FCJ-156 Hacking the Social: Internet Memes, Identity Antagonism, and the Logic of Lulz."

9 Julien, "Bourdieu, Social Capital and Online Interaction", 366 Emphasis original.

${ }^{10}$ Literat and van den Berg, "Buy Memes Low, Sell Memes High: Vernacular Criticism and Collective Negotiations of Value on Reddit's MemeEconomy", 8-9.

${ }^{11}$ Papacharissi and Streeter, "The Habitus of the New."

12 Bourdieu, Distinction, 224. Emphasis added.

${ }^{13}$ Benjamin, "Theses on the Philosophy of History", 258.

${ }_{14}$ Milner, "Media Lingua Franca: Fixity, Novelty, and Vernacular Creativity InInternet Memes", 2.

${ }^{15}$ Herwig, "The Archive as the Repertoire. Mediated and Embodied Practice on Imageboard 4chan.Org", 52.
} 
boards themselves. ${ }^{16} \mathrm{I}$ argue that there should also be attention paid to the materiality of memetic reproduction itself in 4chan's history, and its role in creating an "infrastructure of feeling", part of a constellation of "technological and institutional linkages or systems... central to the organization and functioning of social and cultural life."17 For much of 4chan's "golden age", one of the primary markers of a meme's capital on 4chan was image manipulation and recontextualisation through software such as Photoshop (or many laborious hours in Microsoft Paint). Use of stock generators, such as those found on memegenerator.net, were held in disdain, as were as content aggregators such as Icanhascheezburger. To rely upon such outsider sources for memetic worth illustrated the users' disconnect with the ethos of the board: they needed to "lurk moar". The burden of knowledge was privatised, with users expected to keep an extensive personal archive of memes at-hand. ${ }^{18} \mathrm{~A}$ common topic of thread on 4 chan at this time was concerned with the size and girth of meme folders, with users asked to either provide a screenshot of the amount of disk space it occupies (often Photoshopped to comically large sizes), or to show their best, most select image from it.

Taken together, the means and forms of participation on 4chan build a particular temporality, the emergent state of which demands user vigilance and active participation. Whilst ostensibly accessible to all and encouraging of democratic participation, not only does the extensive racist and misogynistic content on 4chan serve as barrier to entry, but the forms of popular meme-making on 4chan take often reinforce this divide. ${ }^{19}$ The need for extensive personal archive as well as specific technical proficiency continues to favour users with desktop computers and a surplus of free time, as well as privilege a white masculine mastery over technological forms. This is further reflected in the recent adoption of the term disparaging term "phoneposting", referring to the perception that low-quality content is posted from users browsing 4chan on phones. ${ }^{20}$ Recalling Benjamin's XIII Thesis, we should critique this crude, pseudo-social Darwinist vision of memetic progress that is presenced on 4chan. ${ }^{21}$ Although the culture of anonymity and lack of formal content rating system has been held to create a modern-day agora, where any user may speak (through memes) and be judged solely by the quality of their content, 4chan is better known today as a space "inclusive to the disparate factions of the far-right". ${ }^{22}$ I argue that this is linked to the

\footnotetext{
${ }^{16}$ Knuttila, "User Unknown: 4chan, Anonymity and Contingency."

${ }^{17}$ Coleman, "Theorizing the Present: Digital Media, Pre-Emergence and Infra-Structures of Feeling", 11.

${ }^{18}$ Manivannan, "Attaining the Ninth Square: Cybertextuality, Gamification, and Institutional Memory on 4chan."

${ }^{19}$ Manivannan, "Tits or GTFO:The Logics of Misogyny on 4chan's Random - /b/."

20 "/qa/ - What's Wrong with Phone Posting? - Question \& Answer."

${ }^{21}$ Benjamin, "Theses on the Philosophy of History", 260.

22 Poole, "Meme Factory"; Thompson, "The Measure of Hate on 4Chan."
} 
memetic temporal politics of "futural thrust towards a new era" alongside "a diagnosis of the world-historical situation as one of crisis and decline". ${ }^{23}$

With the decline of /b/ - Random, and subsequent rise of /pol/ - Politics, it is notable that the focus of content production on 4chan has largely shifted from making memes to remaking the world memetically. This is, in part, a reaction to a nebulously defined "Endless Summer", referring to an influx of new, undisciplined users to the site and the supposed breakdown in cultural coherency that it signified. Accompanying this was a commercial appropriation and codification of meme production by outsiders, such as Icanhazcheeseburger and Know Your Meme, and subsequent loss of cultural cache as the Internet's meme factory to "Normie" platforms such as Facebook, Tumblr, and Twitter. While paranoia about degradation of board quality has been a constitutive part of 4 chan since its inception, the locus of control shifting from $/ \mathrm{b} /$ to $/ \mathrm{pol} / \mathrm{has}$ changed its fetish-object from intracultural exclusivity outward to crises of white masculinity. ${ }^{24}$ The notion of an Endless Summer functions as a stab-in-the-back myth, with the prelapsarian inner truth and greatness of 4chan "a mythic source of eternal values for its ultra-dynamic drive to conquer the future". ${ }^{25}$ Theirs is a revolutionary conservatism that understands "what it would 'conserve' is already lost (if indeed it ever existed, which is doubtful), and hence must be created anew" ${ }^{26}$ Through a watchful shepherding of its historical ontology, "the change presents itself fully to realise this 'past' for the first time". ${ }^{27}$ In the valorisation of a Hobbesian meme war and perpetual "operations" against its enemies, users are provided the opportunity for post-fascist palingenesis, a redemption through rebirth overcoming "decadence, betrayal, humiliation and victimhood". ${ }^{28}$ The previous subtext of white masculine domination is made text in their pseudo-ironic embrace of open fascism. Memes can be good. ${ }^{29}$ But /b/ was never good; there "is not a document of [its] civilization which is not at the same time a document of [its] barbarism". ${ }^{30}$

\footnotetext{
${ }^{23}$ Griffin, "Fixing Solutions: Fascist Temporalities as Remedies for Liquid Modernity", 15; Osborne, The Politics of Time: Modernity and Avant-Garde, 163.

${ }^{24}$ Chebrolu, "Modular Whiteness: 4chan's /Pol/ as Habitual Enjoyment of Crisis."

${ }^{25}$ Griffin, "Fixing Solutions: Fascist Temporalities as Remedies for Liquid Modernity", 15.

${ }^{26}$ Osborne, The Politics of Time: Modernity and Avant-Garde, 164.

27 Ibid., 164.

${ }^{28}$ el-Ojeili, "Reflecting on Post-Fascism: Utopia and Fear", 5.

${ }^{29}$ See, for example, Frazer and Carlson, "Indigenous Memes and the Invention of a People"; Phillips and Milner, "Decoding Memes: Barthes' Punctum, Feminist Standpoint Theory, and the Political Significance of \#yesallwomen”; Breheny, "'By Any Memes Necessary': Exploring the Intersectional Politics of Feminist Memes on Instagram."

${ }^{30}$ Benjamin, "Theses on the Philosophy of History", 256.
} 
Bibliography

"/qa/ - What's Wrong with Phone Posting? - Question \& Answer." 4chan, October 12, 2016. https://yuki.la/qa/876200.

Benjamin, Walter. "Theses on the Philosophy of History." In Illuminations, translated by Harry Zohn, 253-65. New York: Schocken Books, 1968.

Bourdieu, Pierre. Distinction. Translated by Richard Nice. Cambridge, Mass.: Harvard University Press, 1984.

Breheny, Caitlin. "'By Any Memes Necessary': Exploring the Intersectional Politics of Feminist Memes on Instagram", Master's Thesis, (Uppsala University, 2017)

Chebrolu, Rishi. "Modular Whiteness: 4chan's /Pol/ as Habitual Enjoyment of Crisis." presented at the 16th Annual Cultural Studies Association Conference, Pittsburgh, June 1, 2018.

Coleman, Gabriella. "Net Wars over Free Speech, Freedom, and Secrecy or How to Understand the Hacker and Lulz Battle against the Church of Scientology." presented at the The Next Hope, New York, July 17, 2009. http://www.tagtele.com/videos/voir/62946.

Coleman, Rebecca. "Theorizing the Present: Digital Media, Pre-Emergence and Infra-Structures of Feeling." Cultural Studies 32, no. 4 (December 20, 2017): 1-23. doi:10.1080/09502386.2017.1413121.

el-Ojeili, Chamsy. "Reflecting on Post-Fascism: Utopia and Fear." Critical Sociology, May 8, 2018, 089692051876886. doi:10.1177/0896920518768867.

Foucault, Michel. "What Is Enlightenment?" In The Foucault Reader, edited by Paul Rabinow, 32-51. New York: Vintage, 1984.

Frazer, Ryan, and Bronwyn Carlson. "Indigenous Memes and the Invention of a People." Social Media + Society 3, no. 4 (October 2017): 205630511773899. doi:10.1177/2056305117738993.

Griffin, Roger. "Fixing Solutions: Fascist Temporalities as Remedies for Liquid Modernity." Journal of Modern European History 13, no. 1 (2015): 5-23. doi:10.17104/1611-8944_2015_1_5.

Grossberg, Lawrence. We Gotta Get Out of This Place. New York and London: Routledge, 1992.

Herf, Jeffrey. Reactionary Modernism: Technology, Culture and Politics in Weimar and the Third Reich. Cambridge: Cambridge University Press, 1984.

Herwig, Jana. "The Archive as the Repertoire. Mediated and Embodied Practice on Imageboard 4chan.Org." In Mind and Matter: Comparative Approaches Toward Complexity, edited by Gunther Friesinger, Johannes Grenzfurthner, and Thomas Ballhausen, 39-56. Bielefeld: Transcript, 2011. 
Julien, Chris. "Bourdieu, Social Capital and Online Interaction." Sociology 49, no. 2 (April 2015): 356-73. doi:10.1177/0038038514535862.

Knuttila, Lee. "User Unknown: 4chan, Anonymity and Contingency." First Monday 16, no. 10 (September 19, 2011). doi:10.5210/fm.v16i10.3665.

Literat, loana, and Sarah van den Berg. "Buy Memes Low, Sell Memes High: Vernacular Criticism and Collective Negotiations of Value on Reddit's MemeEconomy." Information, Communication \& Society, August 22, 2017, 1-18. doi:10.1080/1369118X.2017.1366540.

Manivannan, Vyshali. "Attaining the Ninth Square: Cybertextuality, Gamification, and Institutional Memory on 4chan." Enculturation, no. 14 (October 10, 2012).

_. "Tits or GTFO:The Logics of Misogyny on 4chan's Random - /B/." The Fibreculture Journal, no. 22 (2013): 109-32.

Milner, Ryan M. "FCJ-156 Hacking the Social: Internet Memes, Identity Antagonism, and the Logic of Lulz." The Fibreculture Journal, 2013.

_. "Media Lingua Franca: Fixity, Novelty, and Vernacular Creativity InInternet Memes." Selected Papers of Internet Research 14 (2013): 1-5. https://spir.aoir.org/index.php/spir/article/view/806/390.

Nissenbaum, Asaf, and Limor Shifman. "Internet Memes as Contested Cultural Capital: The Case of 4chan's /b/ Board." New Media \& Society 19, no. 4 (April 2017): 483-501. doi:10.1177/1461444815609313.

Osborne, Peter. The Politics of Time: Modernity and Avant-Garde. London: Verso, 1995.

Papacharissi, Zizi, and Thomas Streeter. "The Habitus of the New." Culture Digitally, October 16, 2012. http://culturedigitally.org/2012/10/the-habitus-of-the-new/.

Phillips, Whitney, and Ryan M Milner. "Decoding Memes: Barthes' Punctum, Feminist Standpoint Theory, and the Political Significance of \#yesallwomen." In Entertainment Values, edited by Stephen Harrington, 195-211. London: Palgrave Macmillan UK, 2017. doi:10.1057/978-1-137-47290-8_13.

Poole, Christopher. "Meme Factory." presented at the Paraflows Symposium 2009, Vienna, September 12, 2009.

https://digiom.wordpress.com/2010/04/06/moot-on-4chan-and-why-it-works-as-a-m eme-factory/.

Swiatek, Lukasz. "Constructing Cultural Memory: A Memetic Approach." International Journal of Media \& Cultural Politics 12, no. 1 (March 1, 2016): 129-42. doi:10.1386/macp.12.1.129_1.

Thompson, Andrew. "The Measure of Hate on 4Chan." Rolling Stone, May 10, 2018. https://www.rollingstone.com/politics/politics-news/the-measure-of-hate-on-4chan-6 27922/. 